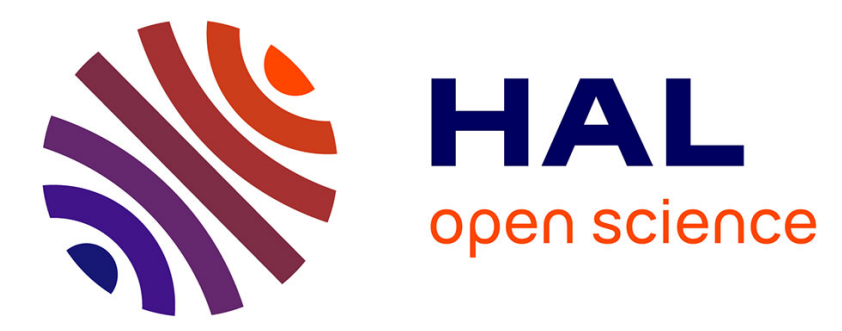

\title{
New ways to measure the work function difference in MOS structures
}

\author{
S.K. Krawczyk, H.M. Przewlocki, A. Jakubowski
}

\section{To cite this version:}

S.K. Krawczyk, H.M. Przewlocki, A. Jakubowski. New ways to measure the work function difference in MOS structures. Revue de Physique Appliquée, 1982, 17 (8), pp.473-480. 10.1051/rphysap:01982001708047300 . jpa-00245024

\section{HAL Id: jpa-00245024 https://hal.science/jpa-00245024}

Submitted on 1 Jan 1982

HAL is a multi-disciplinary open access archive for the deposit and dissemination of scientific research documents, whether they are published or not. The documents may come from teaching and research institutions in France or abroad, or from public or private research centers.
L'archive ouverte pluridisciplinaire HAL, est destinée au dépôt et à la diffusion de documents scientifiques de niveau recherche, publiés ou non, émanant des établissements d'enseignement et de recherche français ou étrangers, des laboratoires publics ou privés. 


\title{
New ways to measure the work function difference in MOS structures (*)
}

\author{
S. K. Krawczyk $\left({ }^{* *}\right)\left({ }^{+}\right)$, H. M. Przewłocki $\left({ }^{* * *}\right)$ and A. Jakubowski $\left({ }^{* *}\right)$
}

$\left({ }^{* *}\right)$ Institute of Electron Technology, Technical University of Warsaw, Koszykowa 75, 00-662 Warsaw, Poland

(***) Institute of Electron Technology, Al. Lotników 32/46, 02-668 Warsaw, Poland

(Reçu le 22 septembre 1981, révisé les 29 mars et 4 mai 1982, accepté le 6 mai 1982)

\begin{abstract}
Résumé. - On a élaboré deux nouvelles méthodes de détermination du potentiel de contact dans les structures MOS. On a mis ces méthodes en pratique et les valeurs de $\phi_{\text {MS }}$ obtenues par elles ainsi que celles d'autres auteurs s'accordent bien. Les méthodes sont simples et plus faciles à appliquer que celles généralement utilisées dans la détermination de $\phi_{\mathrm{MS}}$.
\end{abstract}

\begin{abstract}
Two new techniques for contact potential difference determination in MOS structures have been developed. These techniques were applied in practice yielding $\phi_{M S}$ values remaining in close agreement with each other, and within the range of $\phi_{\mathrm{MS}}$ values obtained by other authors. These techniques are simple and much easier in application then the commonly used methods of $\phi_{\mathrm{MS}}$ determination.
\end{abstract}

1. Introduction. - The work function difference (WFD) in MOS structures is the difference of the energy required to raise an electron from the Fermi level in the semiconductor to the conduction band of the insulator $\left(q \varphi_{\mathrm{Si}}\right)$, and the energy $\left(q \varphi_{\mathrm{m}}\right)$ required to raise an electron from the Fermi level in the gate material to the conduction band in the insulator.

The contact potential difference (CPD) in MOS structures $\phi_{\mathrm{MS}}$ is correspondingly defined here, for the flat band situation, as :

$$
\phi_{\mathrm{MS}}=\varphi_{\mathrm{m}}-\varphi_{\mathrm{Si}}
$$

where $\varphi_{\mathrm{m}}$ and $\varphi_{\mathrm{Si}}$ are potential barrier heights at the gate material-insulator, and semiconductor insulator interfaces, as shown in figure 1 , in which other potentials used in this work are also indicated. Both $\varphi_{\mathrm{m}}$ and $\varphi_{\mathrm{Si}}$ are considered here to be positive values, in accordance with the sign convention commonly used in the literature of the subject [1-10] $\left({ }^{1}\right)$.

The value of $\phi_{\mathrm{Ms}}$ is an important parameter of any MOS device. Basic electrical characteristics of MOS

(*) Communication présentée à l'ESSDERC 1981.

$\left({ }^{+}\right)$Currently with Laboratoire d'Electronique, Automatique et Mesures Electriques, Ecole Centrale de Lyon, 36, av. G. de Collongue, 69130 Ecully, France.

( $\left.{ }^{1}\right)$ This sign convention is different from the one used in our previous papers $[14,15]$.

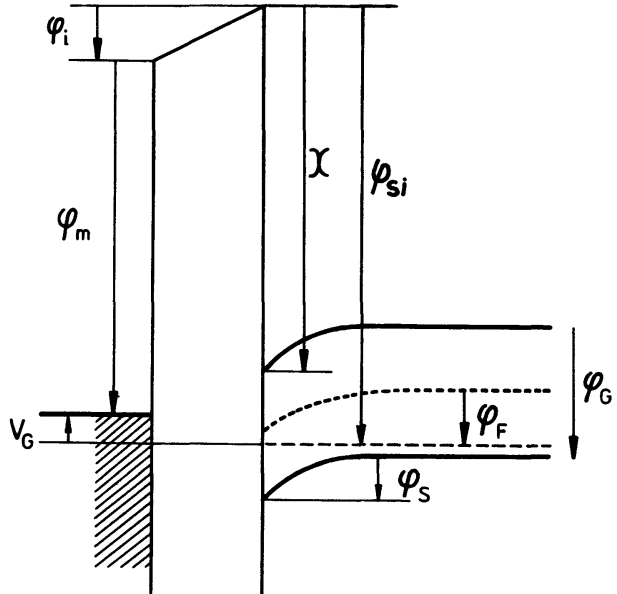

Fig. 1. - The band diagram of the MOS structure. The potentials used in this work are indicated.

integrated circuits and transistors depend on the value of $\phi_{\text {MS }}$. In particular, the threshold voltage $V_{\mathrm{T}}$, which is a fundamental parameter of these devices, may often be expressed by the following formula $\left({ }^{2}\right)$ :

$$
V_{\mathrm{T}}=\phi_{\mathrm{MS}}-\frac{Q_{\text {eff }}}{C_{\mathrm{i}}}+2 \varphi_{\mathrm{F}}-\frac{Q_{\mathrm{B}}}{C_{\mathrm{i}}}
$$

(2) In case of more sophisticated MOS transistor designs, more involved formulae are used, but the dependence of $V_{T}$ on $\phi_{\mathrm{MS}}$ remains essentially the same. 
where $Q_{\text {eff }}$ and $Q_{\mathrm{B}}$ are respectively, the effective charge of the insulating layer $\left({ }^{3}\right)$, and depletion layer charge at the onset of strong inversion (per unit area), $C_{\mathrm{i}}$ is the insulator capacitance (per unit area), and $\varphi_{\mathrm{F}}$ is the electrostatic potential in the semiconductor bulk (see Fig. 1). The first two factors in this expression for $V_{\mathrm{T}}$, yield the value of the flat band voltage $V_{\mathrm{FB}}$, which is a gate voltage at which the energy bands in the semiconductor substrate are flat up to the semiconductor-insulator interface. Namely :

$$
V_{\mathrm{FB}}=\phi_{\mathrm{MS}}-\frac{Q_{\mathrm{eff}}}{C_{\mathrm{i}}} .
$$

In connection with equation (3) it is worthwhile to note that in the early days of MOS devices (in the sixties), the main contribution to the flat band voltage was due to the fixed oxide charge $Q_{\mathrm{f}}$ (and sometimes to other oxide and interface charges either), as illustrated schematically in figure 2 . This situation stimulated many scientific programs and numerous research works, aimed at better understanding and better control of the oxide charges. The scale of this worldwide research effort is clearly illustrated by the bibliography of this, and related subjects, compiled by

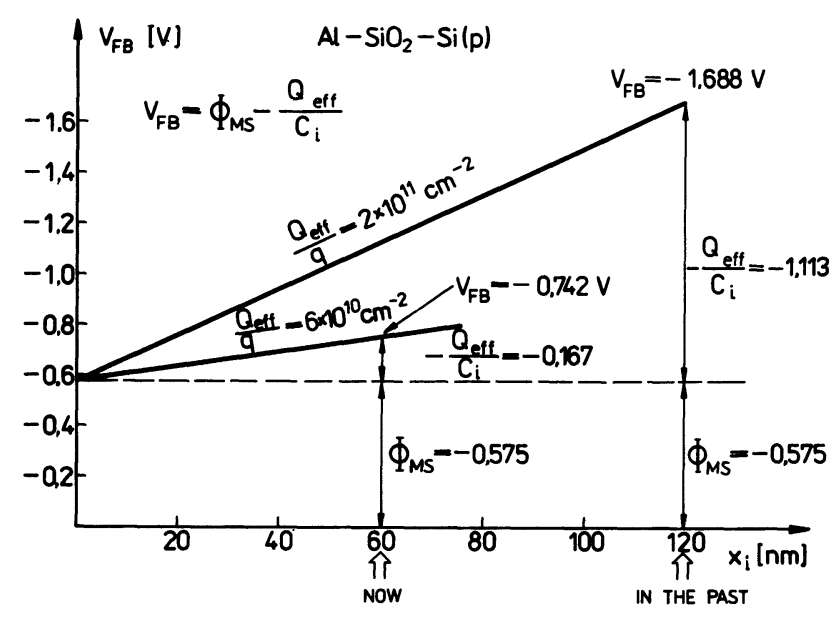

Fig. 2. - Schematic illustration of the contributions of $\phi_{\mathrm{MS}}$ and $Q_{\mathrm{eff}} / C_{\mathrm{i}}$ to the value of $V_{\mathrm{FB}}$, in the past, and at present.

$\left({ }^{3}\right)$ The effective charge of the insulating layer is defined by the following formula [16 :

$$
Q_{\text {eff }}=Q_{\mathrm{f}}+Q_{\mathrm{it}}+\frac{1}{x_{\mathrm{i}}} \int_{0}^{x_{\mathrm{i}}} x \rho_{\mathrm{ot}}(x) \mathrm{d} x+\frac{1}{x_{\mathrm{i}}} \int_{0}^{x_{\mathrm{i}}} x \rho_{\mathrm{m}}(x) \mathrm{d} x
$$

in which $Q_{\mathrm{f}}, Q_{\mathrm{it}}$ are the surface densities of the fixed insulator charge, and interface trapped charge, $\rho_{\mathrm{ot}}, \rho_{\mathrm{m}}$ are the volume densities of insulator trapped charge and mobile ionic charge [11], $x$ is the coordinate perpendicular to the gateinsulator and insulator-semiconductor interfaces $(x=0$ at gate-insulator, and $x=x_{i}$ at insulator-semiconductor interfaces). Usually, in MOS structures applied in practice, the fixed oxide charge $Q_{\mathrm{f}}$ is a dominating factor in the total $Q_{\text {eff }}$ value.
Agajanian [12], while the current understanding of these phenomena was summarized by Deal [13]. Resulting from this effort, is a much better control of oxide charges, and lower values of $Q_{\text {eff }}$ typically obtained in manufacturing of MOS devices. Much less attention has been paid till now to the CPD contribution to the flat band voltage since $\phi_{\text {Ms }}$ was usually treated as a fundamental property of the gate and substrate materials used.

Lower $Q_{\mathrm{f}}$ values, together with higher insulator capacitances usually obtained in modern "scaled down " MOS devices, have led to the situation often observed in nowadays MOS products - in which $\phi_{\mathrm{MS}}$ becomes the dominating factor in the value of the flat band voltage, as shown in figure 2.

This fact, and the differences in $\phi_{\mathrm{MS}}$ values obtained by various authors (as discussed below), indicate the need for better understanding of the CPD behaviour in MOS structures.

2. Measurement results and measurement techniques reported in the literature. - In modern MOS circuits, the absolute values of threshold voltages are often lower than $1 \mathrm{~V}$, in which case there is a strong influence of $\phi_{\mathrm{MS}}$ on the value of $V_{\mathrm{T}}$. In such cases it is particularly important to know the exact value of the CPD between the semiconductor substrate and the gate material. In spite of that, $\phi_{\mathrm{MS}}$ values given in the literature [5-10] differ considerably. This fact is illustrated in figure 3, for the $\mathrm{Al}-\mathrm{SiO}_{2}-\mathrm{Si}$ system, to which the experimental part of this work is limited.

As can be seen in figure 3, the values obtained by Werner [6] for the $\mathrm{Al}^{-} \mathrm{SiO}_{2}-\mathrm{Si}$ (n-type) system are more than $0.4 \mathrm{~V}$ higher than the values obtained by Kar [7]. Moreover, according to [6] the values of $\phi_{\text {MS }}$ are positive in this case (for the range of substrate doping applied in practice), while other authors claim it is negative $[5,7]$. Various reasons have been proposed to explain the differences in $\phi_{M S}$ values obtained by the above mentioned authors. Haberle and Fröschle [8] found the CPD to depend on the silicon substrate orientation in such a way, that $\phi_{\text {MS }}$ becomes more positive in case of $\langle 100\rangle$ orientation, than in the case of $\langle 111\rangle$ orientation of the silicon substrate. Gaind and Kasprzak [9] explain the differences in $\phi_{\mathrm{MS}}$ values reported in the literature, by the differences in MOS structure processing conditions, on the basis of atomic hydrogen chemisorption at the $\mathrm{Si}_{-} \mathrm{SiO}_{2}$ interface. The dependence of $\phi_{M S}$ on MOS system processing conditions was supported by our results reported in [14] and [15]. Hickmott [10] discussed the influence of the dipole layers that exist at the $\mathrm{Si}_{-} \mathrm{SiO}_{2}$, and metal-SiO ${ }_{2}$ interfaces, or the dipole layers in the oxide, on the effective value of CPD. He pointed out at the complex phenomena that can take place at the metal-SiO ${ }_{2}$ interface, which may influence the effective $\phi_{\mathrm{Ms}}$ values. In the literature available to the authors of this work no mention however was found concerning the changes in the effective $\phi_{\mathrm{MS}}$ value resulting 


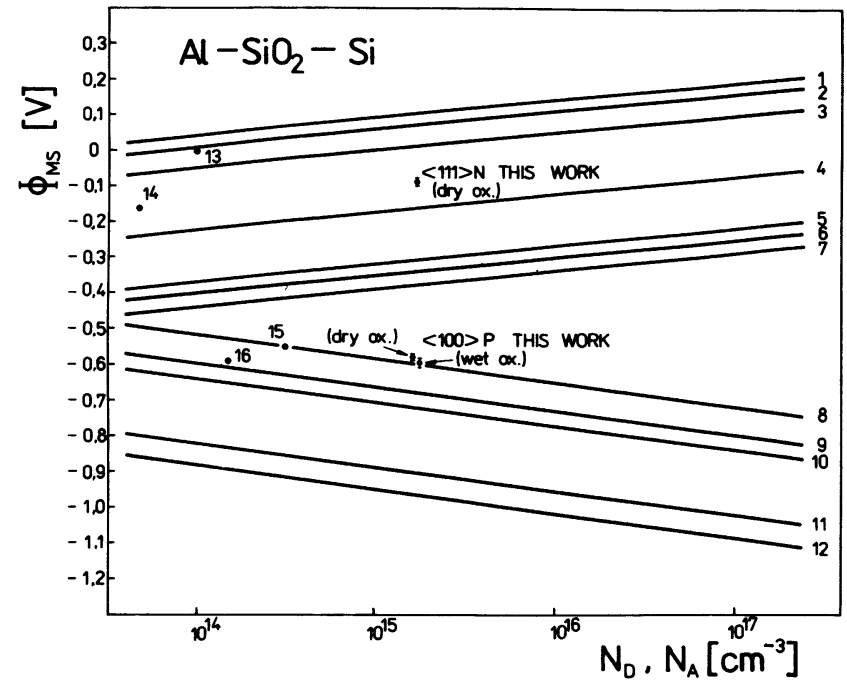

Fig. 3. - Results of $\phi_{\mathrm{MS}}$ measurements obtained by various authors for differently processed $\mathrm{Al}-\mathrm{SiO}_{2}-\mathrm{Si}$ structures. Results of earlier works are shown as $\phi_{\mathrm{Ms}} v s$. substrate doping $\left(N_{\mathrm{D}}\right.$ or $\left.N_{\mathrm{A}}\right)$ lines. Results obtained recently by Hickmott [10] and the results obtained in this work are shown by circles indicating the average values, while vertical bars indicate standard deviations of results obtained for one group of identically processed samples. (1) reference [8], substrate orientation $\langle 100\rangle$, Si (n-type); (2) [6], $\langle 100\rangle$, Si(n); (3) [9], $\langle 100\rangle, \operatorname{Si}(n)$; (4) [9], $\langle 100\rangle, \operatorname{Si}(n) ;(5)[5],\langle 100\rangle$, $\langle 111\rangle, \mathrm{Si}(\mathrm{n}) ;(6)[8],\langle 111\rangle, \mathrm{Si}(\mathrm{n}) ;(7)[7],\langle 100\rangle, \mathrm{Si}(\mathrm{n})$; (8) [6], $\langle 100\rangle, \operatorname{Si}(\mathrm{p}) ;(9)[9],\langle 100\rangle, \operatorname{Si}(\mathrm{p}) ;(10)[9],\langle 111\rangle$, $\mathrm{Si}(\mathrm{p})$; (11) [5], $\langle 100\rangle,\langle 111\rangle, \mathrm{Si}(\mathrm{p})$; (12) [7], $\langle 100\rangle$, $\mathrm{Si}(\mathrm{p})$; (13) [10], $\langle 100\rangle, \mathrm{Si}(\mathrm{n})$; (14) [10], $\langle 111\rangle, \mathrm{Si}(\mathrm{n})$; (15) [10], $\langle 100\rangle, \operatorname{Si}(\mathrm{p}) ;(16)[10],\langle 111\rangle, \operatorname{Si}(\mathrm{p}) ;((13),(14)$, (15), (16) - samples annealed in forming gas, $\left.400^{\circ} \mathrm{C}\right)$.

from carrier trapping in the oxide layer, as described below. Nearly all the results of $\phi_{\mathrm{Ms}}$ measurements mentioned above, and shown in figure 3 , were obtained using various forms of the classical method of flat band voltage determination for MOS capacitors with varying thickness of the dielectric layer $[3,4]$. This method is based on equation (3). Which (if we assume that $Q_{\text {eff }} \simeq Q_{\mathrm{f}}$ ) may be rewritten in the following form :

$$
V_{\mathrm{FB}}=\phi_{\mathrm{MS}}-\frac{Q_{\mathrm{f}}}{\varepsilon_{\mathrm{i}}} x_{\mathrm{i}}
$$

where $x_{\mathrm{i}}$, and $\varepsilon_{\mathrm{i}}$ are the insulating layer thickness, and permittivity of the insulator, respectively. The values of $V_{\mathrm{FB}}$ are measured for a series of MOS capacitors differing only in the thickness $x_{i}$ of the oxide layer (otherwise the capacitors are assumed to be identical), and plotted against the $x_{i}$ value for each capacitor, yielding a straight line, as given by (4). The extrapolation of this line to $x_{i}=0$, gives :

$$
V_{\mathrm{FB}}=\phi_{\mathrm{MS}} \quad\left(\text { for } x_{\mathrm{i}}=0\right)
$$

allowing $\phi_{\mathrm{MS}}$ determination for the measured series of MOS capacitors. The advantages and limitations of this measurement technique are discussed in detail in [3, 4] and [6-10]. In our opinion, the main limitations of this method are :

- the amount of preparatory work required to obtain one measurement result (one $\phi_{\mathrm{MS}}$ value),

- the requirement that the MOS capacitors of one series (usually $5 \ldots 8$ capacitors were used), differ only in the thickness of the dielectric layer $x_{i}$, being otherwise identical.

In their pioneering work on $\phi_{\mathrm{MS}}$ determination [5], Deal et al. used photoelectric measurement of barrier heights at both $\mathrm{Si}-\mathrm{SiO}_{2}$ and metal-SiO ${ }_{2}$ interfaces. From the difference of these heights they determined CPD for six groups of MOS structures with gates made of six different metals. Also, using the so obtained $\mathrm{Al}-\mathrm{SiO}_{2}$ barrier height, they determined $\phi_{\mathrm{Ms}}$ values and barrier heights for MOS structures with gates made of other metals. This was done by comparing the $C(V)$ characteristics of MOS structures which were assumed to differ only in the gate material. In this case the displacement between the $C(V)$ characteristic of a given MOS structure and the $C(V)$ characteristic of the $\mathrm{Al}_{-} \mathrm{SiO}_{2}-\mathrm{Si}$ structure is due to the difference in metal-SiO ${ }_{2}$ barrier heights, which can be so determined. Measurements reported in [5] were made on samples with $\mathrm{p}$ and $\mathrm{n}$ silicon substrates of $\langle 100\rangle$, and $\langle 111\rangle$ orientations. No differences in barrier heights, which might be attributed to silicon orientation were observed, and the barrier height values were reproducible to $0.1 \mathrm{~V}$. The application of methods used in [5] for $\phi_{\text {MS }}$ determination is limited since the photoelectric method is not accurate enough to compensate for the difficulties involved in its application. The comparative method of $C(V)$ characteristics, on the other hand, is based on the assumption that the gate material constitutes the only difference between capacitors whose characteristics are compared, and very often, this is not the case.

3. New contact potential difference determination methods. - 3.1 THE PRINCIPLE OF THE PROPOSED METHODS. - Trying to explain the difference in $\phi_{\text {Ms }}$ values found in the literature, new CPD measurement methods have been suggested recently $[14,15]$, and are further developed in this work.

The balance of potentials in the MOS structure is given by :

$$
V_{\mathrm{G}}-\varphi_{\mathrm{m}}=\varphi_{\mathrm{i}}-\chi-E_{\mathrm{G}} / 2 q-\varphi_{\mathrm{F}}+\varphi_{\mathrm{s}}
$$

where the various potentials used are defined in figure 1.

The contact potential difference $\phi_{\text {MS }}$ can be expressed in the following way:

$$
\phi_{\mathrm{MS}}=\varphi_{\mathrm{m}}-\chi-E_{\mathrm{G}} / 2 q-\varphi_{\mathrm{F}} .
$$


Combining equations (6) and (7), yields the following relation :

$$
V_{\mathrm{G}}=\varphi_{\mathrm{i}}+\varphi_{\mathrm{s}}+\phi_{\mathrm{MS}}
$$

The idea of the proposed methods of $\phi_{\mathrm{MS}}$ determination is based on the fact that if we find the gate voltage $V_{\mathrm{GO}}$ at which the potential drop across the insulating layer equals zero $V_{\mathrm{GO}}=V_{\mathrm{G}}\left(\varphi_{\mathrm{i}}=0\right)$, and the surface potential $\varphi_{\mathrm{so}}=\varphi_{\mathrm{s}}\left(\varphi_{\mathrm{i}}=0\right)$, corresponding to $V_{\mathrm{GO}}$, than, the CPD can be easily obtained as :

$$
\phi_{\mathrm{MS}}=V_{\mathrm{GO}}-\varphi_{\mathrm{so}} .
$$

The proposed methods offer additionally as it is shown later, the possibility of separate determination of the $Q_{\text {eff }}$ value.

In this work two methods of separate determination of $\phi_{\mathrm{MS}}$ and $Q_{\text {eff }}$ values are described. The common step in both of them is the determination of the $V_{\mathrm{GO}}$ value by photoelectric method (see section 3.2). The proposed methods differ in the procedure of $\varphi_{\mathrm{so}}$ determination. In one of them (method I) the $\phi_{\mathrm{MS}}$ and $Q_{\text {eff }}$ values are obtained from the measured $V_{\text {GO }}$ and $V_{\mathrm{FB}}$ values. In the second one (method II) these values are calculated from measured $V_{\mathrm{GO}}$ and $C\left(V_{\mathrm{GO}}\right)$ values.

Since $V_{\mathrm{GO}}$ and $\varphi_{\mathrm{so}}$ are determined under illumination conditions, the effect of light induced generation on the properties of semiconductor surface region should be taken into account, in calculation of $\varphi_{\mathrm{so}}$ and $Q_{\text {eff }}$ from the $C(V)$ data. This problem is discussed in section 3.3.

3.2 The TEChNiQUe of $V_{\text {GO }}$ DeTERMination. - The value of $V_{\mathrm{GO}}$ can be measured using a photoelectric method of Viswanathan and Ogura [17], illustrated in figure 4 , in which a current-voltage $I_{G}\left(V_{G}\right)$ characteristic of UV illuminated MOS capacitor is monitored. The illumination is such that gate current consists of electrons excited from the gate material or from the semiconductor into the conduction band of the dielectric. This current changes sign for $\varphi_{\mathrm{i}}=0$ (which happens for $V_{G}=V_{G O}$ ), allowing determination of the $V_{\mathrm{GO}}$ value.
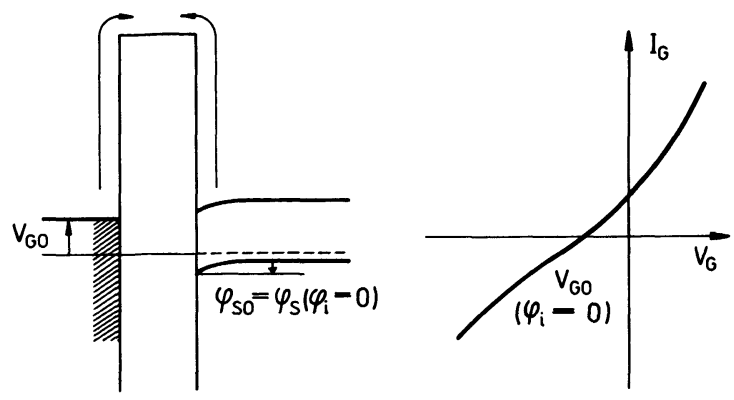

Fig. 4. - Illustration of the photoelectric method used to measure the gate voltage $V_{\mathrm{GO}}$, at which potential drop across the insulating layer equals zero $\left(\varphi_{i}=0\right)$.
3.3 SEMICONDUCTOR SURFACE REGION UNDER ILLUMINATION CONDITIONS. - The influence of illumination on electrical properties of a MOS structure has already been analysed in a number of works [e.g. 18-23]. In [22, 23] it was shown, that phenomena occurring in a MOS structure under illumination can be described in a similar way as for the same structure in the dark, provided the Fermi potential $u_{\mathrm{F}}=\varphi_{\mathrm{F}} q / k T$ is replaced by effective Fermi potential $u_{\mathrm{F}}^{*}=\varphi_{\mathrm{F}}^{*} q / k T$ and the intrinsic concentration $n_{\mathrm{i}}$, by effective intrinsic concentration $n_{\mathrm{i}}^{*}$. The $u_{\mathrm{F}}^{*}$ and $n_{\mathrm{i}}^{*}$ are defined by equations (10) and (11), respectively :

$$
\begin{aligned}
& u_{\mathrm{F}}^{*}=\frac{1}{2} \ln \left[\frac{\xi+\mathrm{e}^{u_{\mathrm{F}}}}{\xi+\mathrm{e}^{-u_{\mathrm{F}}}}\right] \\
& n_{\mathrm{i}}^{*}=n_{\mathrm{i}}\left[\left(\xi+\mathrm{e}^{u_{\mathrm{F}}}\right)\left(\xi+\mathrm{e}^{-u_{\mathrm{F}}}\right)\right]^{1 / 2}
\end{aligned}
$$

where $\xi$ is the effective level of light-induced generation defined as :

$$
\xi=\frac{\Delta n}{n_{\mathrm{i}}}=\frac{\Delta p}{n_{\mathrm{i}}}
$$

and where $\Delta n, \Delta p$ are the concentrations of excess carriers assumed to be equal to each other and constant in the semiconductor surface region. Such conditions occur when minority carrier diffusion length is greater than space charge region width and when quasi-Fermi levels are flat in the semiconductor surface region, i.e. when quasi-equilibrium conditions prevail in MOS structure under illumination. If this can be assumed the values of $u_{\mathrm{F}}^{*}$ and $n_{\mathrm{i}}^{*}$ do not depend on the band curvature, and they can be considered as parameters describing properties of semiconductor surface region under given illumination conditions. The assumptions adopted in this theory were formulated and verified in [22, 23]. All these assumptions are fulfilled in the conditions under consideration.

The value of $u_{\mathrm{F}}^{*}$ can be calculated from the MOS capacitance $C_{\min }$ under illumination in the strong inversion conditions (per unit area), by solving the following equation $[22,23]$ :

$$
\frac{1}{C_{\min }}=\frac{1}{C_{\mathrm{i}}}+\frac{1}{\varepsilon_{\mathrm{s}}} \sqrt{\frac{4 \varepsilon_{\mathrm{s}} k T\left|u_{\mathrm{F}}^{*}\right|}{q^{2} N}}
$$

where $\varepsilon_{\mathrm{s}}$ is the semiconductor permittivity, $q$ is the electronic charge and $N$ stands for the dopant concentration.

Having found $u_{\mathrm{F}}^{*}$, the effective level of light-induced generation $\xi$ can be evaluated from equation (10). Inserting the value of $\xi$ into equation (11) the effective intrinsic concentration $n_{i}^{*}$ can be calculated.

Thus, for the illuminated MOS capacitor, the total charge $Q_{\mathrm{s}}^{*}$ in the semiconductor surface region may be calculated from the following equation :

$$
Q_{\mathrm{s}}^{*}=2 q n_{\mathrm{i}}^{*} L_{\mathrm{D}}^{*} F_{\mathrm{s}}\left(u_{\mathrm{s}}, u_{\mathrm{F}}^{*}\right)
$$


where $L_{\mathrm{D}}^{*}$ is the intrinsic Debye length under illumination conditions

$$
L_{\mathbf{D}}^{*}=\sqrt{\frac{k T \varepsilon_{\mathrm{s}}}{2 q^{2} n_{\mathrm{i}}^{*}}}
$$

where $k$ is Boltzmann constant, $T$ is temperature, and the Kingston function $F_{s}$ is given by $\left({ }^{4}\right)$ :

$$
\begin{aligned}
F_{\mathrm{s}}=-\frac{u_{\mathrm{s}}}{\left|u_{\mathrm{s}}\right|}\left[\mathrm{e}^{-u_{\mathrm{F}}^{*}}\left(\mathrm{e}^{u_{\mathrm{s}}}-u_{\mathrm{s}}-1\right)+\right. \\
\left.+\mathrm{e}^{u_{F}^{*}}\left(\mathrm{e}^{-u_{\mathrm{s}}}+u_{\mathrm{s}}-1\right)\right]^{1 / 2}
\end{aligned}
$$

where

$$
u_{\mathrm{s}}=\frac{q \varphi_{\mathrm{s}}}{k T} \quad \text { and } \quad u_{\mathrm{F}}^{*}=\frac{q}{k T} \varphi_{\mathrm{F}}^{*} .
$$

3.4 DETERMINATION OF $\phi_{\text {MS }}$ FROM THE $V_{\text {GO AND }}$ $V_{\mathrm{FB}}$ VALUES. - Two situations, illustrated in figure 5 will be considered now. The first situation (Fig. 5a) is the flat band situation in the semiconductor, meaning that $\varphi_{\mathrm{s}}=0$, in which case

$$
V_{\mathrm{G}}=V_{\mathrm{FB}}=\varphi_{\mathrm{io}}+\phi_{\mathrm{MS}}
$$

where $\varphi_{\mathrm{io}}=\varphi_{\mathrm{i}}\left(\varphi_{\mathrm{s}}=0\right)$.

The value of $\varphi_{\mathrm{io}}$ may be expressed as :

$$
\varphi_{\mathrm{io}}=-\frac{Q_{\mathrm{eff}}}{C_{\mathrm{i}}} .
$$

Substituting equation (18) into equation (17), yields the expression for the flat band voltage $V_{\mathrm{FB}}$, given by equation (3).

The second situation of interest (Fig. $5 b$ ) takes place when the potential drop across the insulating layer equals zero $\left(\varphi_{i}=0\right)$. In this case :

$$
V_{\mathrm{G}}=V_{\mathrm{GO}}=\varphi_{\mathrm{so}}+\phi_{\mathrm{MS}}
$$

where $\varphi_{\mathrm{so}}=\varphi_{\mathrm{s}}\left(\varphi_{\mathrm{i}}=0\right)$.

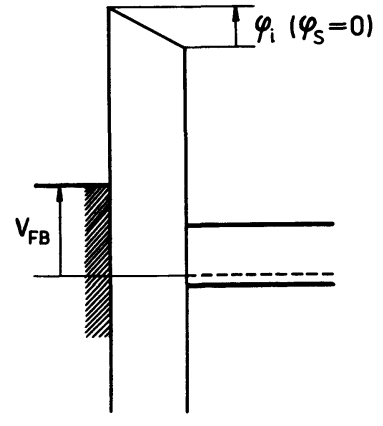

(a)

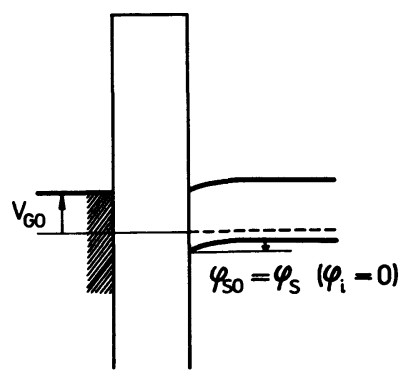

(b)
Fig. 5. - The energy band diagrams of the MOS structure at two different gate voltages : $a) V_{\mathrm{G}}=V_{\mathrm{FB}}\left(\right.$ i.e. $\left.\varphi_{\mathrm{s}}=0\right)$; b) $V_{\mathrm{G}}=V_{\mathrm{GO}}\left(\right.$ i.e. $\varphi_{\mathrm{i}}=0$ ).

( $\left.{ }^{4}\right)$ The quantities $\varphi_{\mathrm{F}}, u_{\mathrm{F}}, n_{\mathrm{i}}, L_{\mathrm{D}}, Q_{\mathrm{s}}$ for illumination conditions are denoted here by symbols with asterisks.
In this situation, the total charge in the semiconductor surface region $Q_{\mathrm{s}}^{*}\left(\varphi_{\mathrm{so}}\right)$ exactly balances the effective charge of the insulating layer $Q_{\text {eff }}$ :

$$
Q_{\text {eff }}=-Q_{\mathrm{s}}^{*}\left(\varphi_{\mathrm{so}}\right)
$$

and is given by Kingston formula, for the illumination conditions given by equation (14).

The difference between equation (19) and equation (3) is given by :

$$
V_{\mathrm{GO}}-V_{\mathrm{FB}}=\varphi_{\mathrm{so}}+\frac{Q_{\mathrm{eff}}}{C_{\mathrm{i}}}
$$

or keeping in mind that $Q_{\text {eff }}=-Q_{s}^{*}\left(\varphi_{\text {so }}\right)$ by the following equation

$$
V_{\mathrm{GO}}-V_{\mathrm{FB}}=\varphi_{\mathrm{so}}-\frac{Q_{\mathrm{s}}^{*}\left(\varphi_{\mathrm{so}}\right)}{C_{\mathrm{i}}}
$$

It is interesting to note, that the value of $V_{\mathrm{GO}}-V_{\mathrm{FB}}$ difference depends on the value of $Q_{\text {eff }}$, but does not depend on $\phi_{\text {MS }}$.

Substituting equations (14-16) into equation (22) the value of $\varphi_{\mathrm{so}}$ can be calculated provided that $V_{\mathrm{GO}}$, $V_{\mathrm{FB}}\left({ }^{5}\right)$ and also $u_{\mathrm{F}}^{*}$ and $n_{\mathrm{i}}^{*}$ have been previously determined. Having found $\varphi_{\mathrm{so}}$ the value of $\phi_{\mathrm{MS}}$ can be calculated from equation (9), and the value of $Q_{\text {eff }}$ from equations (14-16) and (20) ${ }^{6}$ ).

3.5 Determination OF $\phi_{\mathrm{MS}}$ FROM $V_{\mathrm{GO}}$ AND $C\left(V_{\mathrm{GO}}\right)$ VALUES. - The value of $\varphi_{\text {so }}$ can be found by measuring the capacitance of the MOS structure at $V_{\mathrm{GO}}$ gate voltage and using the well known relation between surface potential and capacitance of the semiconductor surface region $[3,4]$. In this case $u_{F}^{*}$ instead of $u_{F}$ and $n_{i}^{*}$ instead of $n_{\mathrm{i}}$ should be inserted into the expression for the Kingston function as given by equation (16).

In the majority of cases, however, significant simplification of the calculations can be made.

In some structures (e.g. typical $\mathrm{Al}_{-}-\mathrm{SiO}_{2}-\mathrm{Si}$ (p-type) system) $V_{G O}$ lies in the depletion or inversion range, and in such cases the following simplified relation can usually be applied $[22,23]$ :

$$
\varphi_{\mathrm{so}}=\frac{\varepsilon_{\mathrm{s}} q N}{2\left[C_{\mathrm{s}}\left(V_{\mathrm{GO}}\right)\right]^{2}}
$$

where $C_{\mathrm{s}}\left(V_{\mathrm{GO}}\right)$ is the capacitance of the semiconductor surface region (per unit area).

When the value of $V_{G O}$ lies in the accumulation range (e.g. for typical $\mathrm{Al}_{-} \mathrm{SiO}_{2}-\mathrm{Si}$ (n-type) system),

$\left(^{5}\right)$ The simplest and most reliable way to measure $V_{\text {FB }}$ is the standard method of $C(V)$ characteristics [3, 4], although other methods $[24,25]$ can also be used.

${ }^{6}$ ) Simple programs have been developed for hand-held programmable calculators allowing calculation of $\varphi_{\mathbf{s o}}$ $Q_{\text {eff }}$ and $\phi_{\mathrm{MS}}$ for MOS systems of known values of $V_{\mathrm{GO}}$ and $V_{\mathrm{FB}}$, substrate doping, and dielectric capacitance. 
the simplified relation between $C_{\mathrm{s}}\left(V_{\mathrm{GO}}\right)$ and $u_{\mathrm{so}}$ is given by :

$$
C_{\mathrm{s}}\left(V_{\mathrm{GO}}\right)=\sqrt{\frac{\varepsilon_{\mathrm{s}} q^{2} N}{2 k T}} \frac{\mathrm{e}^{u_{\mathrm{so}}}-1}{\left(\mathrm{e}^{u_{\mathrm{so}}}-u_{\mathrm{so}}-1\right)^{1 / 2}} .
$$

This equation can be solved numerically for $u_{\text {so }}$.

The capacitance of the semiconductor surface region $C_{\mathrm{s}}\left(V_{\mathrm{GO}}\right)$ can be obtained from the high-frequency $C(V)$ characteristics of MOS capacitor under consideration, using the formula :

$$
C_{\mathrm{s}}\left(V_{\mathrm{Go}}\right)=\frac{C_{\mathrm{i}} \cdot C\left(V_{\mathrm{Go}}\right)}{C_{\mathrm{i}}-C\left(V_{\mathrm{Go}}\right)}
$$

where $C\left(V_{\mathrm{Go}}\right)$ is the MIS capacitance at $V_{\mathrm{Go}}$, per unit area.

Following $\varphi_{\text {so }}$ calculation, the value of $\phi_{\mathrm{MS}}$ can be calculated using equation (9) and the value of $Q_{\text {eff }}$ can be calculated from equations (14-16) and (20).

4. Experimental - In our experiments, the measurements consisted usually of the following steps :

1. Measurement of the insulating layer thickness $x_{\mathrm{i}}$, by ellipsometric methods.

2. Taking of the " primary ", dark, high-frequency $C(V)$ characteristic of the measured MOS structure, from strong accumulation to strong inversion, and taking of the same characteristic in expanded scales to get more precision in reading the $V_{\mathrm{FB}}$ value.

3. Measurement of the MOS capacitance in strong inversion under UV illumination (the wavelength $\lambda=260 \mathrm{~nm}$ was used).

4. Determination of the $V_{G}=V_{G O}$ value, under UV illumination, at which the gate-substrate current goes through zero, and measurement (at the same gate voltage $)$ of the capacitance $C\left(V_{\mathrm{GO}}\right)$ of the illuminated MOS.

5. Taking of the " secondary ", dark, high-frequency $c(v)$ characteristic in expanded scales in order to determine the $V_{\text {FB }}$ value.

Processing of the measurement results, and calculation of the $\phi_{\mathrm{Ms}}$ value was usually pursued in following steps :

1. From the $C(V)$ characteristics (taken in step 2 above) the MOS capacitances $C_{\max }$ (in strong accumulation) and $C_{\min }$ (in strong inversion) are read, from which the doping density $N$, the dielectric capacitance $C_{\mathrm{i}}$, and the flat band capacitance $C_{\mathrm{FB}}$ are calculated by standard methods [3, 4], using the previously determined value of the dielectric thickness $x_{i}$ (step 1 above).

2. The value of MOS capacitance in strong inversion under UV illumination (obtained in step 3 above) is used to calculate the values of $\varphi_{\mathrm{F}}^{*}$, and $n_{\mathrm{i}}^{*}$ (see section 3.3).

3. The values of $V_{\mathrm{GO}}$ (obtained in step 4 above), and $V_{\mathrm{FB}}$ read from the " secondary " $C(V)$ characteristic (taken in step 5 above), and also the values of $u_{\mathrm{F}}^{*}$ and $n_{\mathrm{i}}^{*}$ are used to calculate $\varphi_{\text {so }}$ from equation (22). This allows further calculation of $Q_{\text {eff }}$, and $\phi_{\mathrm{Ms}}$ using equations (14-16), and (9). This procedure of $\phi_{\mathrm{MS}}$ determination is called "Method I", and the results are labelled accordingly.

4. The value of $C\left(V_{\mathrm{GO}}\right)$ (obtained in step 4 above) is used to calculate $C_{\mathrm{s}}\left(V_{\mathrm{GO}}\right)$ from equation (25), and $\varphi_{\text {so }}$ from (23) or (24) as discussed in section 3.5. This again allows calculation of $Q_{\text {eff }}$, and $\phi_{\mathrm{MS}}$ using equations (14-16) and (9). This procedure of $\phi_{M S}$ determination is called "Method II " and the results are labelled accordingly.

The values of $\phi_{\mathrm{MS}}$ have been measured for three groups of different $\mathrm{Al}-\mathrm{SiO}_{2}-\mathrm{Si}$ samples :

- Group VX 28 consisted of MOS samples manufactured using p-type $8.3 \Omega$.cm resistivity silicon substrates of $\langle 100\rangle$ orientation, which were oxidized in a "wet " oxidation atmosphere $\left(\mathrm{O}_{2}+\mathrm{H}_{2} \mathrm{O}\right)\left({ }^{7}\right)$ at temperature $T=1000{ }^{\circ} \mathrm{C}$, to obtain $\mathrm{SiO}_{2}$ layers of thickness $x_{i}=193 \mathrm{~nm}$.

- Group VX 25 consisted of MOS samples made on the same type and orientation of the substrates, which were oxidized in "dry " ambient $\left(\mathrm{O}_{2}\right)$, at temperature $T=1100^{\circ} \mathrm{C}$, to obtain $x_{i}=198 \mathrm{~nm}$.

- Group VX 13 consisted of MOS samples made on n-type, $4.8 \Omega . \mathrm{cm}$ resistivity silicon substrates of $\langle 111\rangle$ orientation, oxidized in dry $\mathrm{O}_{2}$ atmosphere at $T=1100^{\circ} \mathrm{C}$, to obtain $x_{\mathrm{i}}=207 \mathrm{~nm}$.

Formation of $\mathrm{Al}$ gate electrodes for all groups of samples, was made by two step EB blanket evaporation, and standard photolithographic techniques. In the first step, small $(0.5 \mathrm{~mm} \times 0.5 \mathrm{~mm})$ and thick $\left(x_{\mathrm{Al}}=1 \mu \mathrm{m}\right) \mathrm{Al}$ contact pads are formed, while in the second step larger $(1.5 \mathrm{~mm} \times 1.5 \mathrm{~mm})$ semitransparent $\left(x_{\mathrm{Al}}=10 \mathrm{~nm}\right)$ aluminum gates (covering the previously made contact pads) are formed. The remaining processes used in preparation of these groups of samples were made according to the standard procedures used in manufacturing of MOS integrated circuits. Special measures were taken to assure that these processes are identically conducted for all the groups of samples. All the three groups of samples received $15 \mathrm{~min}$. final anneal in pure nitrogen atmosphere at $500{ }^{\circ} \mathrm{C}$.

Between 20 and 40 samples were measured for each group. The measurement results are summarized in table I where average values, and standard deviations are given for the parametres determined by both methods described above.

5. Discussion. - The dispersion of $\phi_{\mathrm{MS}}$ and $Q_{\mathrm{eff}}$ values obtained for one run of identically processed MOS structures is small as seen from the values of standard deviations (see Table I).

The differences between the average values of $\phi_{\mathrm{MS}}$

( $\left.{ }^{7}\right)$ No $\mathrm{Cl}$ containing agents have been added to the oxidation atmospheres used in these experiments. 
Table I. - Summary of measurement results and calculations performed using Method I and Method II. Average values, and standard deviations are given for the surface potential $\varphi_{\mathrm{so}}$, effective charge of insulating layer $Q_{\text {eff }} / q$ and contact potential difference $\phi_{\mathrm{MS}}$.

\begin{tabular}{|c|c|c|c|c|c|c|c|}
\hline & \multicolumn{2}{|c|}{$\begin{array}{c}\mathrm{VX} 28 \\
\mathrm{p}-\mathrm{Si}\langle 100> \\
\text { wet oxide } \\
\varphi_{\mathrm{F}}=0.301 \mathrm{~V}\end{array}$} & \multicolumn{2}{|c|}{$\begin{array}{c}\mathrm{VX} 25 \\
\mathrm{p}-\mathrm{Si}\langle 100\rangle \\
\text { dry oxide } \\
\varphi_{\mathrm{F}}=0.301 \mathrm{~V}\end{array}$} & \multicolumn{2}{|c|}{$\begin{array}{c}\text { VX 13 } \\
\text { n-Si }<111> \\
\text { dry oxide } \\
\varphi_{\mathrm{F}}=-0.290 \mathrm{~V}\end{array}$} \\
\hline & & $\begin{array}{c}\text { Average } \\
\text { value }\end{array}$ & $\begin{array}{l}\text { Std. } \\
\text { dev. }\end{array}$ & $\begin{array}{c}\text { Average } \\
\text { value }\end{array}$ & $\begin{array}{l}\text { Std. } \\
\text { dev. }\end{array}$ & $\begin{array}{c}\text { Average } \\
\text { value }\end{array}$ & $\begin{array}{l}\text { Std. } \\
\text { dev. }\end{array}$ \\
\hline \multirow{3}{*}{ 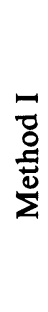 } & $\begin{array}{l}\varphi_{\text {so }} \\
\text { (V) }\end{array}$ & 0.134 & 0.019 & 0.065 & 0.006 & 0.114 & 0.002 \\
\hline & $\underset{\left(\mathrm{cm}^{-2}\right)}{Q_{\mathrm{eff}} / q}$ & $\begin{array}{l}4.88 \times \\
10^{10}\end{array}$ & $\begin{array}{c}4.30 \times \\
10^{9}\end{array}$ & $\begin{array}{l}2.92 \times \\
10^{10}\end{array}$ & $\begin{array}{c}2.00 x \\
10^{9}\end{array}$ & $\begin{array}{l}1.66 \times \\
10^{11}\end{array}$ & $\begin{array}{c}3.53 x \\
10^{9}\end{array}$ \\
\hline & $\begin{array}{l}\phi_{\mathrm{MS}} \\
\text { (V) }\end{array}$ & -0.555 & 0.026 & -0.542 & 0.012 & -0.105 & 0.019 \\
\hline \multirow{3}{*}{ 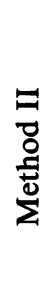 } & $\begin{array}{l}\varphi_{\text {so }} \\
\text { (V) }\end{array}$ & 0.114 & 0.017 & 0.060 & 0.006 & 0.118 & 0.002 \\
\hline & $\begin{array}{c}Q_{\mathrm{eff}} / q \\
\left(\mathrm{~cm}^{-2}\right)\end{array}$ & $\begin{array}{l}4.40 \times \\
10^{10}\end{array}$ & $\begin{array}{c}4.19 x \\
10^{9}\end{array}$ & $\begin{array}{l}2.81 \times \\
10^{10}\end{array}$ & $\begin{array}{c}2.03 x \\
10^{9}\end{array}$ & $\begin{array}{l}1.79 \times \\
10^{11}\end{array}$ & $\begin{array}{l}1.04 \times \\
10^{10}\end{array}$ \\
\hline & $\begin{array}{l}\phi_{\mathrm{MS}} \\
\text { (V) }\end{array}$ & -0.536 & 0.029 & -0.537 & 0.013 & -0.108 & 0.021 \\
\hline
\end{tabular}

obtained by Method I and Method II, are small, and are due to the differences in $\varphi_{\mathrm{so}}$ values obtained by both methods.

The obtained values of $\phi_{\text {Ms }}$ seem to be " reasonable " when compared with the values given by other authors, as shown in figure 3 . The values of $Q_{\text {eff }} / q$ follow the well known dependences on substrate orientation and oxidation conditions (see e.g. [13]), which is an additional proof that both methods yield correct results. It is worthwhile to note that the difference between the average values of $\phi_{\text {Ms }}$ obtained (with both methods) for VX 28 samples (wet oxidation) and VX 25 samples (dry oxidation) is statistically insignificant, at a significance level of $5 \%$, which suggests that the "wetness " of the oxidation atmosphere does not significantly affect $\phi_{\mathrm{MS}}$ values of the samples. It should however be noticed that the dispersion of measurement results is significantly higher for VX 28 samples (wet oxidation) than for the VX 25 samples (dry oxidation).

One of the more important observations made in the course of these measurements is that the value of $\phi_{\text {MS }}$ of a given MOS sample is changed slightly $\left(\Delta \phi_{\mathrm{MS}}=20 \mathrm{mV}-50 \mathrm{mV}\right)$ by the measurement procedure itself. This means, that for several consecutive measurements made on the same sample, one gets higher and higher values of $\phi_{\mathrm{Ms}}$ (or less and less negative values of $\phi_{\mathrm{MS}}$ ), which is not accompanied by significant changes in $Q_{\mathrm{f}}$ values. This effect was proved to be due to the UV illumination used for $V_{\mathrm{GO}}$ measurement, and we attribute it to trapping of electrons excited into the $\mathrm{SiO}_{2}$ conduction band. The observed trend of $\phi_{\mathrm{MS}}$ changes and small values of the observed changes of $Q_{\text {eff }}$ suggest that electron trapping in the neighbourhood of the $\mathrm{Al}-\mathrm{SiO}_{2}$ interface predominates - increasing thus the potential barrier height at the $\mathrm{Al}-\mathrm{SiO}_{2}$ interface. This was confirmed by an independent measurement of $\mathrm{Al}-\mathrm{SiO}_{2}$, and $\mathrm{Si}-\mathrm{SiO}_{2}$ barrier height changes introduced by UV illumination [26] (The Powell-Berglund method of barrier height determination was used $[27,28]$ ).

Preliminary results of experiments with heat treatment of the previously UV illuminated MOS structures show that electrons trapped in $\mathrm{SiO}_{2}$, may be released in a low temperature heat treatment, such as the final anneal applied in preparation of our samples (see section 4). Thus, it seems that using different combinations of processes which promote trapping or detrapping (or more generally introduction or extraction) of charges in the neighbourhood of $\mathrm{Al}$ $\mathrm{SiO}_{2}$, and/or $\mathrm{Si}_{-} \mathrm{SiO}_{2}$ interfaces, a wide range of $\phi_{\mathrm{MS}}$ values may be obtained. This, was probably the main reason for the differences in $\phi_{\text {MS }}$ values obtained by various authors (see Fig. 3). Further work is necessary to fully explain the influence of charge trapping on the values of $\phi_{\mathrm{MS}}$, and the values of various charges in $\mathrm{SiO}_{2}$.

Assuming that the UV illumination influences $\phi_{\text {MS }}$ and does not influence $Q_{\text {eff }}$, the values of $\phi_{\text {MS }}$ obtained in this work (and given in table I), should be corrected for the shift caused by UV illumination. Since in our case the average value of $V_{\mathrm{FB}}$ shift was $\Delta V_{\mathrm{FB}}=0.035 \mathrm{~V}$, the values of $\phi_{\mathrm{MS}}$ of the original samples (before the measurement) used in our experiments, should be $0.035 \mathrm{~V}$ lower (more negative) than the values given for them in table I. The results of our measurements shown in figure 3 are corrected accordingly.

6. Conclusions. -1 . Two new techniques for CPD determination in MOS structures have been developed. These techniques were applied in practice yielding $\phi_{\mathrm{MS}}$ values remaining in close agreement with each other, and within the range of $\phi_{\text {MS }}$ values obtained by other authors.

2. These techniques are simple and much easier in application than the commonly used methods of $\phi_{\mathrm{MS}}$ determination. In particular, only one MOS capacitor is required for measurement of one $\phi_{\mathrm{Ms}}$ value (as opposed to a series of MOS capacitors with different thicknesses of the dielectric layer required for the application of the classical method).

3. The dispersion of $\phi_{\mathrm{MS}}$ and $Q_{\text {eff }}$ values obtained for one run of identically processed MOS structures is small.

4. The accuracy of $\phi_{\text {MS }}$ determination seems to be good in spite of the fact that the measurement tech- 
nique itself introduces a slight change in the $\phi_{\mathrm{MS}}$ value.

5. Changes of the value of $\mathrm{CPD}$ in $\mathrm{Al}-\mathrm{SiO}_{2}-\mathrm{Si}$ structures were observed to occur as a result of charge trapping and detrapping in $\mathrm{SiO}_{2}$. In particular, trapping of electrons in the neighbourhood of the $\mathrm{Al}-\mathrm{SiO}_{2}$ interface, caused by UV illumination of the sample was shown to change the value of $\phi_{\text {MS }}$.

Further work is needed for better understanding of these phenomena, and their importance for the MOS technology.

\section{References}

[1] Herring, C., Nichols, M. H., Thermionic emission. Rev. Mod. Phys. 21 (1949) 185.

[2]' Höltzl, J., Schulte, F. K., Work function of metals. In : Solid Surface Physics (Springer Tracts in Modern Physics) Vol. 85, Berlin (1979).

[3] Grove, A. S., Physics and Technology of Semiconductor Devices (J. Wiley and Sons, New York) 1967.

[4] Sze, S. M., Physics of Semiconductor Devices (J. Wiley and Sons, New York) 1969.

[5] Deal, B. E., Snow, E. H., Mead, C. A., Barrier energies in metal-silicon dioxide-silicon structures. J. Phys. Chem. Solids 27 (1966) 1873.

[6] WeRner, W. M., The work function difference of the MOS system with aluminium field plates and polycrystalline silicon field plates. Solid-State Electron. 17 (1974) 769.

[7] KAR, S., Determination of Si-Metal work function differences by MOS capacitance technique. SolidState Electron. 18 (1975) 169.

[8] Haberle, K., Fröschle, E., On the work function difference in the $\mathrm{Al}-\mathrm{SiO}_{2}-\mathrm{Si}$ system with reactively sputtered $\mathrm{SiO}_{2}$. J. Electrochem. Soc. 126 (1979) 878.

[9] GaIND, A. K., KasprzaK, L. A., Determination of distributed fixed charge in CVD oxide and its virtual elimination by use of $\mathrm{HCl}$. Solid-State Electron. 22 (1979) 303.

[10] Hickmotт, T. W., Dipole layers at the metal-SiO ${ }_{2}$ interfaces. J. Appl. Phys. 51 (1980) 4269.

[11] DEAL, B. E., Standardized terminology for oxide charges associated with thermally oxidized silicon. J. Electrochem. Soc. 127 (1980) 979.

[12] Agajanian, A. H., A bibliography on silicon dioxide films. SCP and Solid State Technol. 20 (1977) 36.

[13] Deal, B. E., Charge effects and other properties of the $\mathrm{Si}-\mathrm{SiO}_{2}$ interface. The current understanding. Proc. of the III International Symposium on Silicon Materials Science and Technology. Philadelphia Pa. May 8-13, 1977.

[14] Przewłocki, H. M., Krawczyk, S., Jakubowski, A. A new technique for accurate determination of work function difference in MOS structures. 10th European Solid State Device Research Conference and 5th Symposium on Solid State Device Technology. York, England, September 1980.

[15] Przewłocki, H. M., Krawczyk, S., Jakubowski, A. A simple technique of work function difference determination in MOS structures. Phys. Status Solidi (a) 65 (1981) 253.

[16] Przewłocki, H. M., Investigation of the influence of technology on $\mathrm{Si}_{-} \mathrm{SiO}_{2}$ system and MOS structure electrical properties. Electron Technology 3 (1970) 103.

[17] Viswanathan, C. R., Ogura, S., Direct measurement of built in voltage in MOS structures. $J$. Appl. Phys. 42 (1971) 5865.

[18] Grosvalet, J., Influence of illumination on MIS capacitance in the strong inversion region. IEEE Trans. Electron. Devices ED-14 (1967) 777.

[19] Pierret, R. H., SAH, C. T., Quantitative analysis of the effects of steady state illumination on the MOS capacitor-theory. Solid-State Electron. 13 (1970) 269.

[20] Pierret, R. H. and SAH, C. T., Quantitative analysis of the effects of steady state illumination on the MOS capacitor-experiment. Solid-State Electron. 13 (1970) 289.

[21] Temple, V. and Schewchun, J., Exact frequency dependent complex admittance of the MOS diode including surface states, SRH impurity effects and lowtemperature dopant impurity response. SolidState Electron. 16 (1973) 93.

[22] JAKUBOWSKI, A. and KRAWCZYK, S., Electrical properties of MIS capacitor under illumination. Electron Technology 11 (1978) 3.

[23] KRAwCZYK, S., Analysis of photoelectric properties of a metal-insulator-semiconductor (MIS) capacitor, Ph. D. Thesis, Dept. of Electronics, Technical University of Warsaw (1980).

[24] Yun, B. H., Direct measurement of flat-band voltage in MOS by infrared excitation. Appl. Phys. Lett. 21 (1972) 194.

[25] Jakubowski, A., KrawCZyK, S., Photoelectric method of the MIS flat band voltage determination. Electron Technology 11 (1978) 23.

[26] LiberadZKa, M., GrabSKI, J., private communication.

[27] Powell, R. J., Interface barrier energy determination from voltage dependence of photoinjected currents. J. Appl. Phys. 41 (1970) 2424.

[28] Berglund, C. N., Powell, R. J., Photoinjection into $\mathrm{SiO}_{2}$ : Electron scattering in the image force potential well. J. Appl. Phys. 42 (1971) 573. 